\title{
Rheological Evaluation of Polymer-Modified Asphalt Binders
}

\author{
Mônica Romero Santos Fernandes ${ }^{\mathrm{a} *}$, Maria Madalena Camargo Forte ${ }^{\mathrm{b}}$, Leni Figueiredo Mathias Leite ${ }^{\mathrm{c}}$

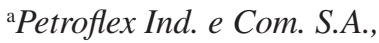 \\ Rua Marumbi 600, 25221-000 Duque de Caxias, RJ - Brazil \\ ${ }^{\mathrm{b}}$ Escola de Engenharia, UFRGS, \\ CP 15010, 91501-970 Porto Alegre - RS, Brazil \\ ${ }^{\mathrm{c}}$ Centro de Pesquisas Leopoldo Américo Miguez de Mello - CENPES, PETROBRAS, \\ Av. Horácio Macedo 950, 12941-915 Rio de Janeiro - RJ, Brazil
}

Received: March 5, 2008; Revised: August 5, 2008

\begin{abstract}
Currently, the most used polymer for asphalt binder modification is the thermoplastic elastomer styrene butadiene styrene (SBS) and aromatic oil is commonly added to the mixtures to improve their compatibly. This paper proposes the use of oil shale from sedimentary rock as a compatibilizer agent for polymer-modified asphalt binder (PMB). PMBs were produced by mixing a bitumen with a linear SBS copolymer $\left(3.5 \%\right.$ (w. $\left.\left.\mathrm{w}^{-1}\right)\right)$ using two oil shale contents ( 2 and $4 \%$ ) and petroleum aromatic oil to evaluate comparatively the effect of the compatibilizer agent on the SBS PMB properties. The rheological characteristics of the SBS PMBs were analyzed in a dynamic shear rheometer (DSR) and the morphology accessed by fluorescence optical microscopy. The viscoelastic behavior of the samples corroborated the results for the classical properties and varied according to the sample morphology and composition. The results indicate that the aromatic and shale oils have similar effects on the microstructure, storage stability and viscoelastic behavior of the PMBs. Thus, shale oil could be successfully used as a compatibilizer agent without loss of properties or could even replace the aromatic oil. Following the Superpave methodology it was observed that the linear- and radial-SBS PMBs and linear-SBS PMB with $2 \%$ of shale oil can be used up to $70{ }^{\circ} \mathrm{C}$, and the linear-SBS PMBs with $4 \%$ of shale oil or $2 \%$ of aromatic oil can be used only up to $64^{\circ} \mathrm{C}$.
\end{abstract}

Keywords: asphalt binder, polymer-modified asphalt, SBS, compatibilizer agent, rheology

\section{Introduction}

Asphalt binders are widely used in road paving ${ }^{1-5}$ and their viscoelastic properties are dependent on their chemical composition. The use of synthetic polymers to modify asphalt binder performance and extend the paving life dates back to the early seventies ${ }^{6-8}$. Important properties such as thermal susceptibility, aging at medium and intermediate temperatures and resistance to rutting and fatigue were improved, and the most successful polymer for asphalt binder modification to date is the styrene-butadiene-styrene (SBS) block copolymers ${ }^{4,7-13}$. These polymers are thermoplastic rubbers and exhibit a two-phase morphology, a glassy phase of the polystyrene terminal blocks, with a glass transition $(\mathrm{Tg})$ around $100{ }^{\circ} \mathrm{C}$, and an elastomeric phase due to the polybutadiene central blocks $\left(\mathrm{Tg} \cong-80^{\circ} \mathrm{C}\right)$. As the paving operating temperature is normally between these two $\mathrm{Tg}$ values, the polystyrene is a rigid domain dispersed in the elastomeric polybutadiene matrix ${ }^{8}$. Since the interaction between the SBS and the asphalt binder occurs by physical rather than chemical bonding, the crosslinking system is reversible even when submitted to many heating and cooling cycles, which makes the SBS polymer a good asphalt modifier ${ }^{4-7}$.

When asphalt binder and SBS are blended, the elastomeric phase (PB) absorbs the asphalt maltene fraction and swells up to nine times its initial volume. At a suitable SBS concentration, normally between 3 to $5 \%$, a polymer network is homogenously formed throughout the asphalt matrix and this changes significantly the asphalt properties ${ }^{5-8}$. On the other hand, as the molecular weights of the polymeric chains are higher than or similar to those of the asphaltenes, they compete for the solvency of the maltene fraction and a phase separation may occur if there is an imbalance between the components. A phase separation indicates incompatibility between the asphalt and polymer and can be avoided by adding aromatic oils ${ }^{7,12}$ or compatibilizer agents to the mixture. However, a high quantity of aromatic oils can dissolve the polystyrene domains and destroy the benefits of the SBS copolymer resulting in a loss of the polymer-modified asphalt binder (PMB) properties ${ }^{14,15}$. Since the storage stability and compatibility are very important properties, the aromatic oil plays an important role in the PMB modified with SBS.

Aromatic oil is a petroleum fraction supplied by refineries and its availability might be reduced in the next few years since there is a high demand for lighter petroleum fractions and thus, it must be cracked in order to increase the production of higher-value petroleum derivatives. Nowadays, sources other than oil crude have been considered as alternative routes for producing petroleum derivatives. Oil shale from sedimentary rock contains bituminous materials that are released as petroleum-like liquids when the rock is heated in the chemical process of pyrolysis. Extracting oil shale from pyrobitumen is more complex than conventional oil recovery and currently is more expensive. However, the Brazilian company PETROBRAS has a consolidated technology Petrosix ${ }^{\circledR}$ for shale extraction (a process called retorting), located in São Mateus do Sul (PR/Brazil) where one of the biggest reserves in the world (Irati formation) is located, and processes 7.800 ton/day of rock producing oil, naphta, gas and other by-products ${ }^{16}$. Because of its chemical nature (low asphaltene and high nitrogen content), bitumen coming from shale oil derived from pyrolysis is an excellent input for asphalt additive production. It can be used to produce wide-spectrum asphalt additives, implementing adhesiveness, weather-resistance and resistance to permanent deformation, increasing the paving resistance and durability.

In the present study shale oil was evaluated as a new potential compatibilizer agent for production of SBS PMB with good prop- 
erties. Shale oil is less volatile and has less aromatic carbons than aromatic oil favoring the polymer binder mixture at high temperature. Shale oil contains basic nitrogen and a small quantity of asphaltenes, these being more saturated compounds than aromatic oil. This could offer the advantage of a better interaction with the PB phase of the SBS. SBS PMB with aromatic oil was also prepared as a reference. The classical and rheological properties of the modified asphalt binders were determined to verify whether any improvement could be achieved through the use of shale oil.

\section{Materials and Methods}

\subsection{Materials}

Paving asphalt CAP 50/70 (Brookfield viscosity $425 \mathrm{cP}$ at $135^{\circ} \mathrm{C}$ ) from São José dos Campos Refinery (SP/Brazil) was used to produce a number of PMB laboratory blends. Two styrene-based copolymers in crumb form with $30 \%$ (w. $\mathrm{w}^{-1}$ ) of styrene, a linear (Coperflex TR 1073) and a radial (Coperflex TR 4071) SBS produced and donated by Petroflex Ind. \& Com. S.A., were used and are shown in Table 1. Aromatic oil, a heavy neutral extract donated by Duque de Caxias Refinery (RJ/Brazil), and shale oil, the AR5 rejuvenator agent donate by the Xisto power plant located in São Mateus do Sul (PR/Brazil), were used as compatibilizer agents.

\subsection{Asphalt binder modification}

All the asphalt-polymer blends were prepared in an appropriate container equipped with a high shear mixer (HSM-1001C, Ross). A known quantity of the asphalt binder was added to the container and heated to $160{ }^{\circ} \mathrm{C}$, followed by the addition of the polymer in the hot asphalt over 5 minutes at $1500 \mathrm{rpm}$. The mixture was continuously stirred for a further 15 minutes under the same conditions and then another 45 minutes at $5000 \mathrm{rpm}$ at a temperature controlled at between 180 and $190{ }^{\circ} \mathrm{C}$. All the runs were prepared with $3.5 \%$ $\left(\mathrm{w} . \mathrm{w}^{-1}\right.$ ) of SBS. For the runs with compatibilizer agent, the shale or aromatic oil was added to hot asphalt $\left(160^{\circ} \mathrm{C}\right)$ before the polymer addition at $500 \mathrm{rpm}$ and the mixture was stirred for 10 minutes. Five SBS PMB mixtures were prepared: four with linear SBS (ML), having $2 \%\left(\mathrm{w} . \mathrm{w}^{-1}\right)$ of aromatic oil (ML2AO), 2 (ML2X) or 4\% (w. $\left.\mathrm{w}^{-1}\right)$ (ML4X) of shale oil and a sample without compatibilizer agent (ML) (CAP + TR 1073). Also, one mixture with radial SBS (MR) (CAP + TR 4071) was prepared. Aromatic oil is also used as a means to obtain PMB penetration values of 40 to $70 \mathrm{dm}$, but in this study, for comparison purposes, $2 \%$ and $4 \%$ was used.

\subsection{Conventional binder tests}

The SBS PMB samples with and without compatibilizer agent were observed under an optical fluorescence microscope (CX41,

Table 1. Linear (L) and radial (R) SBS characteristics.

\begin{tabular}{lcc}
\hline \multicolumn{1}{c}{ Property } & $\mathrm{L}$ & $\mathrm{R}$ \\
\hline Molecular Weight Avg. & 157,169 & 353,164 \\
Polydispersity & 1.07 & 1.08 \\
Diblock content $(\%)$ & - & 14 \\
MFI/200 ${ }^{\circ} \mathrm{C} / 5 \mathrm{~kg}, \mathrm{~g} / 10 \mathrm{~min}$ & 0.17 & - \\
Styrene $(\%)$ & 29.5 & 30.1 \\
Modulus at 300\%, MPa & 2.2 & 3.0 \\
Tensile strength, MPa & 20.5 & 16.5 \\
Elongation $(\%)$ & 750 & 660 \\
Hardness, Shore A & 71 & 82 \\
\hline
\end{tabular}

Olympus) in order to evaluate qualitatively the changes in the morphology as a consequence of the addition and interaction between the components. All of the asphalt binder samples were analyzed through the following classical methods: Penetration (ASTM method D5), Ring and Ball Softening Point (ASTM method D36), Brookfield Viscosity (ASTM method D4402), Storage Stability (ASTM method D7173) and Elastic Recovery using a Ductilometer (ASTM method 6084-97). The elastic recovery test evaluates the ability of the binder to stretch and recover elastically.

\subsection{Ageing procedures}

Short-term laboratory ageing of the pure asphalt binder and SBS PMB mixtures were performed using the Rolling Thin Film Oven Test (RTFOT) (ASTM D method 2872-85). The aged binders were analyzed using a dynamic shear rheometer to evaluate changes in their rheological properties.

\subsection{Dynamic mechanical analysis}

The viscoelastic behavior of the pure asphalt binder and the SBS PMB mixtures were analyzed in a dynamic shear rheometer (DSR CSA II, TA Instruments) following a test procedure and sample preparation method previously described in detail $1^{17,18}$. The tests were undertaken under controlled-strain loading conditions using a temperature sweep between 50 and $80{ }^{\circ} \mathrm{C}$, with a $25 \mathrm{~mm}$ diameter, $1 \mathrm{~mm}$ gap parallel plate testing geometry, frequency of $10 \mathrm{rad} / \mathrm{s}$ and strain of $12 \%$. The strain amplitude was confined within the linear viscoelastic response of the asphalt binder.

The principal viscoelastic parameters obtained from the DSR were the complex shear modulus $\mathrm{G}^{*}$ and the phase angle $\delta$, which are dynamic rheological properties. $\mathrm{G}^{*}$ is defined as the ratio of maximum (shear) stress to maximum strain and represent the material resistance to deformation when subjected to shear loading. It contains elastic and viscous components designated as the storage modulus (G') and loss modulus (G'); respectively. These two components are related to the complex (shear) modulus and to each other through the phase angle $\delta$ which is the phase, or time, lag between the applied shear stress and shear strain responses during a test. When phase angle $\delta$ is $90^{\circ}$ the material can be considered to be purely viscous in nature, whereas a phase angle $\delta$ of $0^{\circ}$ corresponds to purely elastic behavior. Between these two extremes the material behavior can be considered to be viscoelastic in nature, with a combination of viscous and elastic responses.

The pure asphalt binder and SBS PMB samples were also analyzed following the Superpave methodology ${ }^{13}$, developed during the Strategic Highway Research Program (SHRP) in the U.S.A., which considers that rheological properties are better related to the asphalt binder performance than the conventional properties. The Superpave methodology ${ }^{19,20}$ states a performance grade (PG), defined by two temperatures, which indicates the temperature range for use of an asphalt binder in paving. Using this methodology the highest temperature at which the asphalt binder can be used is that where the $\mathrm{G}^{*} / \mathrm{sen} \delta$ value of the sample is higher than $1.0 \mathrm{kPa}$ before, and $2.2 \mathrm{kPa}$ after the aging test. For example, a PG 70-10 indicates that the binder must be used from -10 to $+70{ }^{\circ} \mathrm{C}$ for a good performance paving, the $\mathrm{G}^{*} / \mathrm{sen} \delta$ values being in this case, and at $70^{\circ} \mathrm{C}$, higher than 1.0 and $2.2 \mathrm{kPa}$, for the asphalt binder before and after the aging test, respectively.

\section{Results and Discussion}

All of the asphalt binder samples in this study were submitted to the same heating treatment to avoid any difference in their properties caused by the high temperature used during their preparation. The 
SBS $(3.5 \%)$ and aromatic oil $(2.0 \%)$ content added to the asphalt was the same as that currently used in commercial road paving. No modification to the process conditions was necessary when shale oil was added to the asphalt binder and there was no variation in the mixture viscosity. A PMB modified with radial SBS free of compatibilizer agent was prepared to evaluate the effect of the polymer structure on the asphalt binder performance.

The compatibility of the components in the SBS PMB or the effect of the compatibilizer agents was qualitatively evaluated by comparing the morphology or the sample fluorescence micrographs. The extension or degree of interaction between the components can be related to a higher or lower homogeneity in the shape and distribution of the light areas (corresponding to the polymer) in a dark matrix (the asphalt) ${ }^{6,9,13,21}$. The SBS PMB sample images are shown in Figure 1. There is more homogeneity in the micrograph of the SBS PMB modified with linear-SBS (Figure 1-ML) compared with the sample modified with radial-SBS (Figure 1-MR), in which the light areas are larger and longer. Thus, it is possible to infer that for the mix conditions here employed, the linear-SBS is better dispersed than the radial-SBS due to a more favored interaction between the SBS linear structure and the maltene asphalt fraction. An even better homogeneity of the shape and distribution of the light areas was observed for the linear-SBS PMB with compatibilizer agents, showing that they affected the interaction or compatibility between the polymer and asphalt binder. The linear-SBS PMB samples containing shale oil (Figure 1: ML2X and ML4X) were very different to those with aromatic oil (Figure 1: ML2AO). The light areas in the former were much more homogeneous and clear, showing a higher efficiency of the shale oil in dispersing the polymer in the asphalt. Although the linear-SBS PMB with aromatic oil (Figure 1: ML2AO) also showed an improved morphology, the light areas are larger and not well dispersed indicating that the compatibilizer agent had
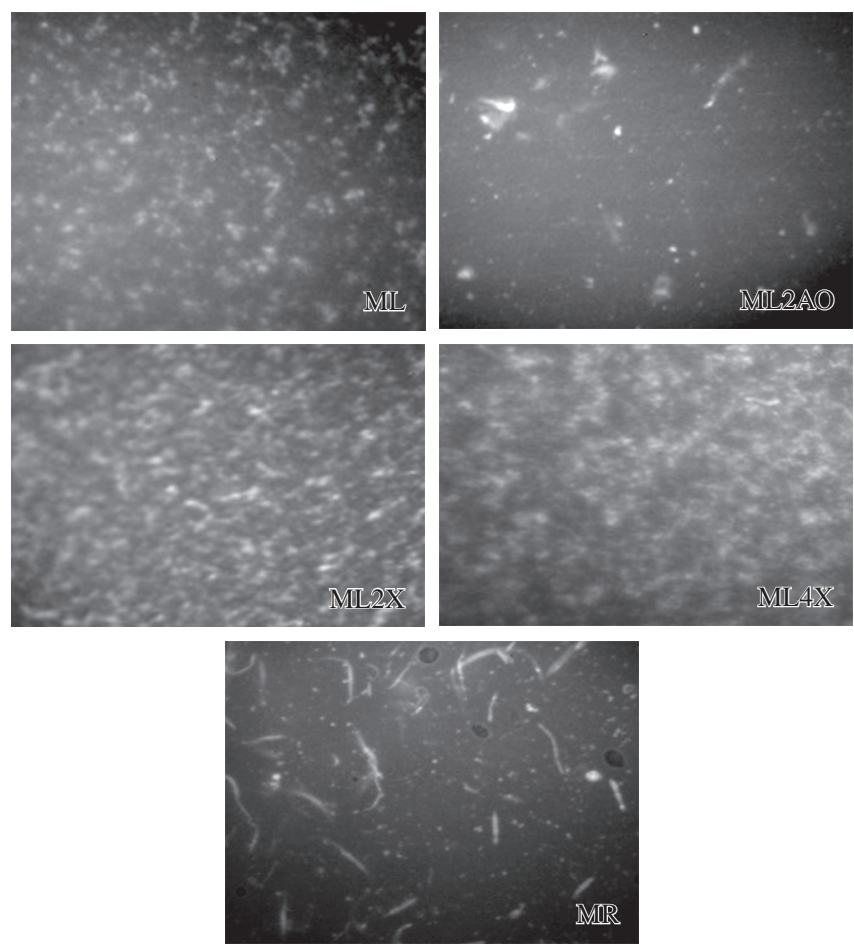

Figure 1. Fluorescence micrographs of the linear-SBS PMB (ML), linearSBS PMB with aromatic (ML2AO) and shale (ML2X, ML4X) oils and radial-SBS PMB (MR). a weaker influence. The better results obtained in the fluorescence analysis for the SBS PMB samples with shale oil can be attributed to a better interaction between the oil and the SBS block copolymer, which has $70 \%\left(\mathrm{w}^{-1} \mathrm{w}^{-1}\right)$ of polybutadiene (PB), as a consequence of the shale oil chemical composition. The shale oil is slightly more polar and saturated than the aromatic oil which could be an advantage regarding the $\mathrm{PB}$ blocks joined by the $\mathrm{PS}$ dominions, facilitating their swelling process at 180 to $190{ }^{\circ} \mathrm{C}$, and promoting a more effective polymer network ${ }^{21}$ in the asphalt. This result suggests that the effect of the shale oil composition on the polymer swelling process must be investigated further.

The effect of SBS polymer modification on the conventional binder properties and the effect of the compatibilizer agent on the SBS PMB can be seen in Table 2. It can be observed that there is a decrease in penetration and an increase in the softening point with the polymer addition and an inverse effect on these properties with the oil addition. As expected, the modified asphalt samples had a reduced penetration and higher softening point and elastic recovery indicating an improvement in the asphalt binder stiffness and flexibility. These modified samples are thus more adequate for paving applications, since they will be more resistant to rutting, fatigue and plastic deformation. Even with a low level of polymer dispersion in the asphalt, as previously indicated by a less uniform homogeneity in the fluorescence micrograph, the conventional properties of the radial-SBS PMB are superior to those of the linear-SBS PMB. The plasticizer effect of the compatibilizer agent increased penetration and lowered the softening point of the linear-SBS PMB to the intermediate values of the pure and modified asphalt. On the other hand, the elastic recovery of the SBS PMB with shale oil was better than that with aromatic oil and the PMB with $4 \%$ of shale oil showed an even better recovery than the linear-SBS PMB.

The values for the Brookfield viscosity of the SBS PMB samples as a function of the SBS structure, compatibilizer agent type and temperature are shown in Figure 2. As expected, there is an increase in the asphalt viscosity with the polymer addition ${ }^{21}$ and it is important to stress that samples with compatibilizer agents, which have a plasticizer effect, showed higher viscosities than the pure asphalt. The Brookfield viscosity variation is in agreement with the softening point values of the SBS PMB. A PMB with high viscosity favors a thicker film formation surrounding the aggregates which increases the cohesive forces between the components and gives the expected improvement in the paving in terms of resistance to water and environmental conditions at operating temperatures. On the other hand, by increasing the temperature the difference in viscosity between the PMB samples decreases, which favors the polymer and compatibilizer mixing during the asphalt modification and paving application.

Phase separation can take place during the PMB storage at elevated temperatures due to differences in the solubility parameters and densities of the phases. At high temperatures and under static

Table 2. Conventional properties of pure and SBS PMB.

\begin{tabular}{lccc}
\hline Sample* & $\begin{array}{c}\text { Penetration } \\
(\mathrm{dmm})\end{array}$ & $\begin{array}{c}\text { Softening } \\
\text { point }\left({ }^{\circ} \mathrm{C}\right)\end{array}$ & $\begin{array}{c}\text { Elastic } \\
\text { recovery }(\%)\end{array}$ \\
\hline CAP 50/70 & 51 & 47 & - \\
ML & 36 & 57 & 80 \\
ML2AO & 42 & 54 & 74 \\
ML2X & 41 & 54 & 77 \\
ML4X & 46 & 54 & 83 \\
MR & 26 & 63 & 88 \\
\hline
\end{tabular}

$* \mathrm{M}=$ mixture; $\mathrm{L}, \mathrm{R}=$ linear, radial $\mathrm{SBS} ; 2 \mathrm{AO}=2 \%$ aromatic oil, $2 \mathrm{X}$, $4 \mathrm{X}=2 \%, 4 \%$ shale oil 
conditions the droplets of the melted SBS disperse in the asphalt agglomerate and float on the top of the asphalt tank $\mathrm{k}^{22}$. As previously reported $^{19,23}$, decreasing differences between the parameters mentioned above reduce the polymer particle migration in the asphalt during the storage time. The addition of oil to the PMB minimizes the migratory process through the SBS swelling which improves the stability of the mixture since the density of the SBS droplets changes, as does the compatibility between the components. The effect of the oil on the stability of the PMB during storage can be evaluated by measuring the softening point of specimens collected from the top and the bottom of an aluminum tube, after pouring the PMB into the tube in a vertical position at $163{ }^{\circ} \mathrm{C}$ for 72 hours and cooling it at room temperature. It was observed that the higher the difference between the softening point of the specimens, the higher the phase separation in the mixture, since the polymer flotation in the PMB increases the softening point of the top specimen. Thus, the difference between the softening points indicates how stable the mixture is. Table 3 shows the softening points of the top and bottom specimens and the difference between these two temperatures. Both shale and aromatic oils improved the storage stability of the PMB showing similar results and the difference between the top and bottom temperatures were in the range of 6 to $8{ }^{\circ} \mathrm{C}$. Therefore, both oils can be used interchangeably without a loss in the PMB storage stability. The differences between the top and bottom softening points for the linear and radial SBS-PMB without oil were around 15 and $26^{\circ} \mathrm{C}$, respectively. This indicates a strong tendency toward phase separation and highlights the need for an improvement when storage is necessary before paving applications.

Table 3. Storage stability of the SBS PMB samples.

\begin{tabular}{lccl}
\hline Sample* & \multicolumn{3}{c}{ Temperature $\left({ }^{\circ} \mathrm{C}\right)$} \\
\hline ML & Top & Bottom & $\left(\mathrm{T}_{\text {Top }}\right)-\left(\mathrm{T}_{\text {hottom }}\right)$ \\
ML2AO & 69.5 & 53.8 & 15.7 \\
ML2X & 59.5 & 52.0 & 7.5 \\
ML4X & 58.0 & 52.0 & 6.0 \\
MR & 58.0 & 51.4 & 6.6 \\
\hline
\end{tabular}

$* \mathrm{M}=$ mixture $\mathrm{L}, \mathrm{R}=$ linear, radial $\mathrm{SBS} ; 2 \mathrm{AO}=2 \%$ aromatic oil, $2 \mathrm{X}$, $4 \mathrm{X}=2 \%, 4 \%$ shale oil

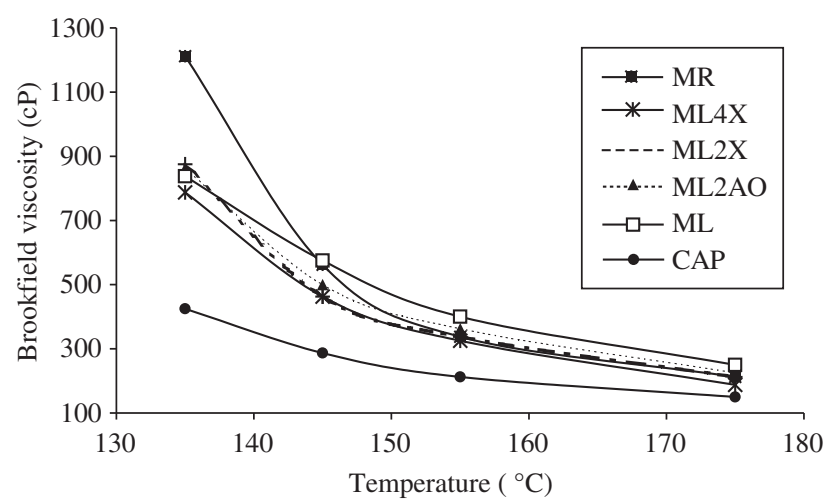

Figure 2. Brookfield viscosity vs. temperature of the pure asphalt binder (CAP), linear- (ML) and radial- (MR) SBS PMB and linear-SBS PMB samples with shale (ML2X, ML4X) and aromatic (ML2AO) oils.
The performance of asphalt paving is dependent on the asphalt binder viscoelastic behavior and the complex modulus $\left(\mathrm{G}^{*}\right)$ and $\tan \delta$ (G'/G') of the PMB prepared in this study were analyzed as a function of the temperature under shear conditions. Tan $\delta$ values were used instead of the complex modulus since they have been considered to be more sensitive to the material composition ${ }^{7}$ and, therefore, to the asphalt modification with other chemical compounds. The plots of $\tan \delta$ vs. temperature, in the range of 50 to $80^{\circ} \mathrm{C}$, for the pure asphalt binder (CAP 50/70), linear- (ML) and radial- (MR) SBS PMB without oil and linear-SBS PMB with shale oil (ML2X and ML4X) and aromatic oil (ML2AO) are shown in Figure 3. The polymer addition to the asphalt caused a considerable reduction in the $\tan \delta$ values as can be seen in Figure $3 \mathrm{a}$ and this result signifies an improvement in the PMB elastic response. The addition of oil to the linear-SBS PMB resulted in a further decrease in the $\tan \delta$ values since this facilitated the swelling of the SBS and promoted its greater dispersion in the asphalt. Also, the plasticizer effect of the oil reduces the asphalt viscosity allowing the polymer network to be more effective. Tan $\delta$ is related to the G'/G' ratio and a decrease in this ratio indicates that the PMB has a higher storage modulus or improved elastic property ${ }^{24}$. Thus, the formation of a polymer network in the asphalt binder leads to a lower plastic deformation.

Figure $3 \mathrm{~b}$ shows, comparatively, in an expanded scale, the tan $\delta$ versus temperature curves of the SBS PMB samples. While $\tan \delta$ increases continuously with temperature for the radial-SBS PMB (MR), the $\tan \delta$ curves tend to form a plateau in the case of the linear-SBS

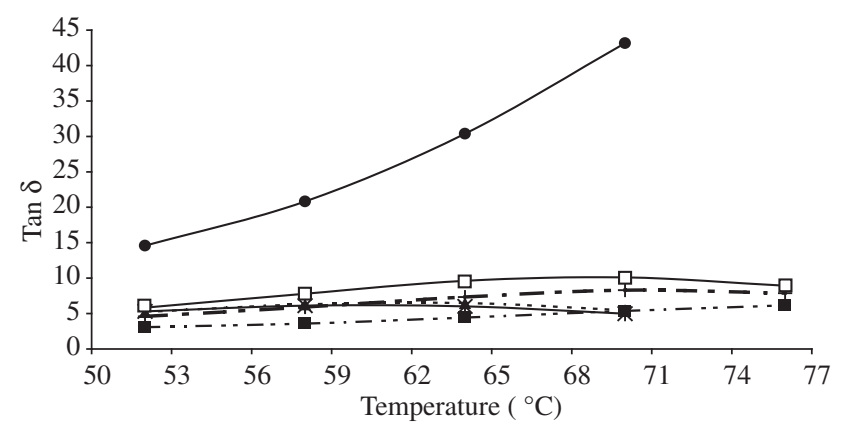

(a)

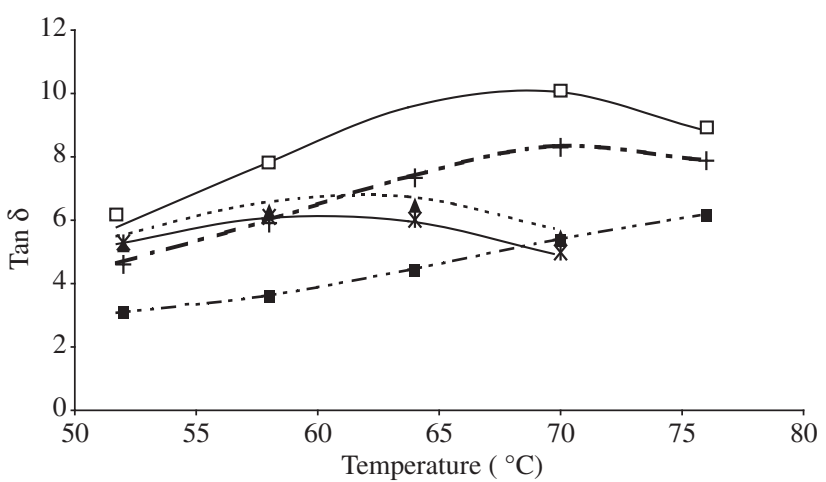

(b)

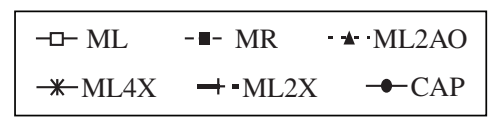

Figure 3. Tan $\delta$ vs. temperature of the pure asphalt binder (CAP), linear- (ML) and radial- (MR) SBS PMB and linear-SBS PMB samples with shale (ML2X, ML4X) and aromatic (ML2AO) oils. a) Normal and b) expanded scales. 
PMB samples (ML, ML2AO, ML2X and ML4X). The linear-SBS PMB samples with $4 \%\left(\mathrm{w} \cdot \mathrm{w}^{-1}\right)$ of shale oil (ML4X) and $2 \%\left(\mathrm{w} \cdot \mathrm{w}^{-1}\right)$ of aromatic oil (ML2AO) had $\tan \delta$ curves equivalent in shape and magnitude and thus they have the same elastic response, revealing the excellent potential of oil shale for use in PMB as a substitute for the aromatic oil currently in use. On the other hand, this curve for the SBS PMB sample with $2 \%$ of shale oil had a shape similar to that of the sample only modified with SBS. There is considerable evidence of extreme polymeric modification at high temperatures with the establishment of a plateau region in the $\tan \delta$ curve of the linear-SBS PMB samples, which is indicative of the formation of a dominant polymer network in the asphalt matrix with decreased viscosity. Thus, in this case, a decrease in the $\tan \delta$ values after the plateau or a maximum value means that the PMB elastic response is still favored at high temperatures and the low viscosity facilitates the efficiency of the swelled elastomeric polymer network in terms of its effect on the viscoelastic behavior, as previously discussed in the literature ${ }^{7}$ for a SBS PMB.

The radial-SBS PMB (MR) showed the lowest $\tan \delta$ values in all temperature ranges and, thus, the best elastic response, although it had the lowest level of SBS dispersion in the asphalt binder, as revealed by the fluorescence micrograph.

The radial-SBS PMB did not show a plateau or a behavior similar to the linear-SBS PMB probably because of the poorer dispersion of the radial-SBS in the asphalt or the swelling capacity of the asphalt maltene fraction. These results show that the radial-SBS dispersion in the asphalt binder was sufficient to improve the PMB elastic response and thus the polymer structure plays an important role in viscoelastic behavior. Also, as expected, there was a higher chemical interaction between the components.

The presence of a plateau in the $\tan \delta$ curve at the paving operating temperatures and the decrease in $\tan \delta$ at higher temperatures reveals that the linear-SBS PMB samples have improved properties, mainly lower thermal susceptibility. It can therefore be inferred that the improved paving performance of the linear-SBS PMB samples will be maintained within a wider range of temperature, and the best results in this respect were obtained with $4 \%$ of shale oil or $2 \%$ of aromatic oil in the PMB, showing these two samples similar behaviors.

Figure 4 shows the decrease in the complex modulus $\left(\mathrm{G}^{*}\right)$ with the temperature of the SBS PMB samples in the range of 50 to $80^{\circ} \mathrm{C}$. The radial-SBS PMB had higher $\mathrm{G}^{*}$ values than the linear-SBS PMB without oil. The effect of the compatibilizer agents on the $\mathrm{G}^{*}$ values for the linear-SBS PMB followed the same pattern observed

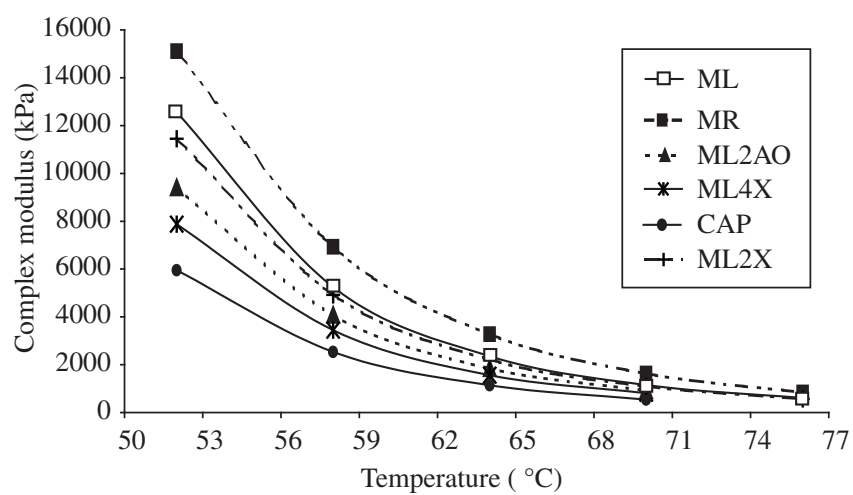

Figure 4. Plots of complex modulus $\mathrm{G}^{*}$ vs. temperature of linear- (ML) and radial- (MR) SBS PMB and linear-SBS PMB samples with shale (ML2X, ML4X) and aromatic (ML2AO) oils. for penetration, Brookfield viscosity and $\tan \delta$, verifying the effect of the shale oil or aromatic oil in terms of plasticizing the sample ${ }^{25}$. The $\mathrm{G}^{*}$ values for all samples show a steep decrease with the temperature increase and tended toward a constant value of the same magnitude regardless of the mixture characteristics or composition. The $\mathrm{G}^{*}$ versus temperature curves do not show any particular variation due to the modification of the PMB samples, which may be related to the viscoelastic behavior of the modified samples or the significant decrease in the sample stiffness with the increase in temperature.

The Superpave methodology can indicate the major stresses observed in asphalt paving such as permanent deformation (rutting), thermal and load-associated fatigue cracking through the rheological parameters described in section 2.4. Figure 5 shows the $\mathrm{G}^{*} / \mathrm{sen} \delta$ versus temperature curves for the pure asphalt binder (CAP 50/70), linear- (ML) and radial- (MR) SBS PMB samples and linear-SBS PMB with shale oil (ML2X and ML4X) and aromatic (ML2AO) oil analyzed with the DSR (a) before and (b) after the aging test. The $\mathrm{G}^{*} / \mathrm{sen} \delta$ values were calculated for the temperatures of $52,58,64$, 70 and $76{ }^{\circ} \mathrm{C}$ and increased during the aging process. However, the difference between the values calculated before and after the aging test was greater at lower temperatures. The higher the temperature of the rheological evaluation the less sensitive is the method in evaluating the viscoelastic response of the sample. The results show that the polymer addition to the asphalt increases significantly the $\mathrm{G}^{*} / \mathrm{sen} \delta$ value and this extends the temperature range within which it can be used. Although, the compatibilizer agent decreases the $\mathrm{G}^{*} / \mathrm{sen} \delta$ values due to the plasticizer effect, these are still sufficiently high and the modified samples can be used within a wider temperature range in comparison to the pure asphalt binder. The $\mathrm{G}^{*} / \operatorname{sen} \delta$ values

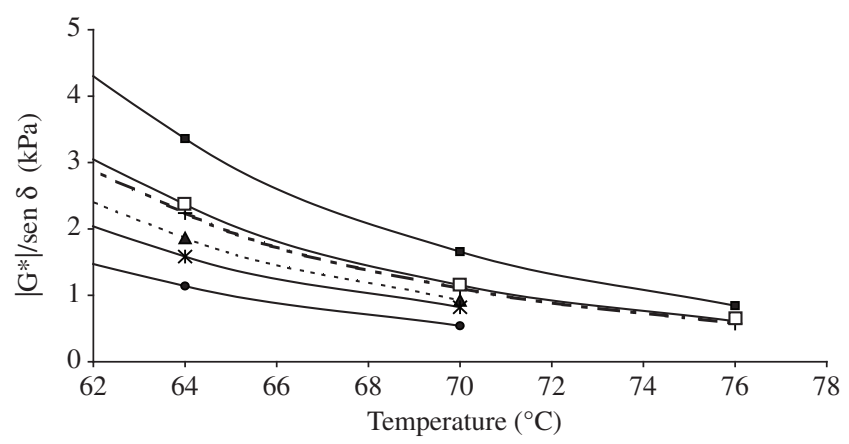

(a)

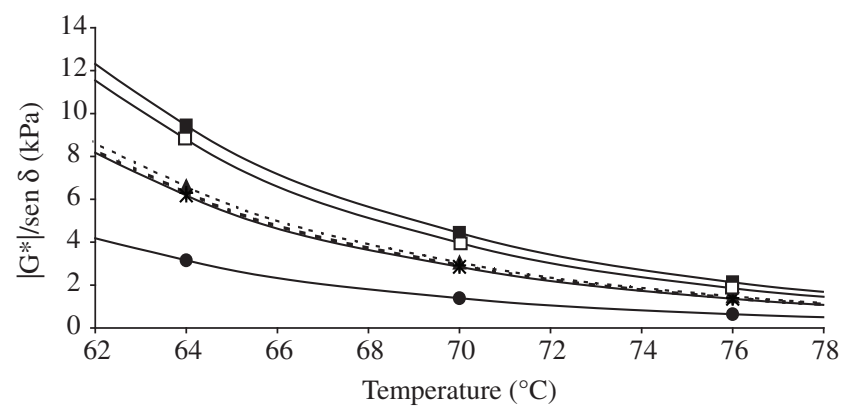

(b)

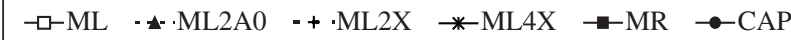

Figure 5. Plots of $\mathrm{G}^{*} / \mathrm{sen} \delta$ vs. temperature of the pure asphalt binder (CAP), linear- (ML) and radial- (MR) SBS PMB and linear-SBS PMB samples with shale (ML2X, ML4X) and aromatic (ML2AO) oils. a) Before and b) after the aging test. 
at the temperatures evaluated for the aged samples with shale oil or aromatic oil were similar. From observing the $\mathrm{G}^{*} / \mathrm{sen} \delta$ values before and after the sample aging it is possible to state that the linear- (ML) and radial- (MR) SBS PMB samples and linear-SBS PMB with $2 \%$ of shale oil (ML2X) can be used below $70{ }^{\circ} \mathrm{C}$, because the $\mathrm{G}^{*} / \mathrm{sen} \delta$ values of these samples at $70^{\circ} \mathrm{C}$ are higher than the values of 1.0 and $2.2 \mathrm{kPa}$ obtained before and after the aging test, respectively. The linear-SBS PMB with $4 \%$ of shale oil (ML4X) and $2 \%$ of aromatic (ML2AO) oil and the pure asphalt binder (CAP) must be used below $64{ }^{\circ} \mathrm{C}$ in order for the $\mathrm{G}^{*} / \mathrm{sen} \delta$ values to remain higher than the above mentioned $\mathrm{G}^{*} / \mathrm{sen} \delta$ values.

\section{Conclusions}

As expected the addition of polymers to asphalt reduces its thermal susceptibility at temperatures close to those used in paving procedures and guarantees a greater constancy of its properties since the asphalt become more elastic (lower $\tan \delta$ ) and stiffer (higher $G^{*}$ ). The effects of the compatibilizer agent on the morphology of the SBS and asphalt mixtures could be easily followed by fluorescence microscopy.

The shale and aromatic oils slightly reduce the conventional and rheological properties of the SBS PMB samples studied. From the fluorescence analysis is was possible to infer that shale oil improves the interaction between the mixture components to a greater extent than aromatic oil. However, the same tendency was not clearly observed in case of the rheological properties. Therefore, the fluorescence analysis was shown to be an effective way to observe the polymer distribution in the asphalt binder, although an improvement in this distribution cannot be correlated with a better rheological performance of the PMB. This finding was corroborated by the radialSBS PMB results for which the fluorescence micrograph indicated a poorer polymer distribution than those of the linear-SBS PMB with and without compatibilizer, but for which better results were obtained for the rheological properties.

Although the results for the conventional properties of the SBS PMB with the addition of shale oil or aromatic oil were similar, the rheological properties did not indicate the best SBS PMB sample in terms of the viscoelastic behavior. The linear SBS-PMB with $4 \%\left(\mathrm{w} . \mathrm{w}^{-1}\right)$ of shale oil or $2 \%\left(\mathrm{w} . \mathrm{w}^{-1}\right)$ of aromatic oil had the same $\tan \delta$ results or elastic response, and therefore, shale oil can be used in asphalt as a good compatibilizer agent or could even replace the aromatic oil in SBS-modified binders.

On the other hand, using the Superpave methodology, which considers the $\mathrm{G}^{*} / \mathrm{sen} \delta$ value, it was observed that the linear- (ML) and radial- (MR) SBS PMB samples and linear-SBS PMB with 2\% of shale oil (ML2X) can be used at temperatures up to $70{ }^{\circ} \mathrm{C}$. The linear-SBS PMB with $4 \%$ of shale oil (ML4X) or $2 \%$ of aromatic (ML2AO) oil, and even the pure asphalt binder (CAP), can be used only at temperatures up to $64{ }^{\circ} \mathrm{C}$.

\section{Acknowledgements}

The authors thank PETROBRAS, PETROFLEX Ind. e Com. S.A and the Governmental Agencies CNPq and CAPES for their financial support.

\section{References}

1. Polacco G, Stastna J, Biondi D, Zanzotto L. Relation between polymer architecture and nonlinear viscoelastic behavior of modified asphalts. Current Opinion in Colloid and Interface Science. 2006; 11(4):230-245.

2. Pérez-Lepe A, Martinez-Boza FJ, Gallegos O, Muñoz ME, Santamaría A. Influence of the processing conditions on the rheological behavior of polymer modified bitumen. Fuel. 2003; 82(11):1339-1348.
3. García-Morales M, Partal P, Navarro FJ, Martíez-Boza F, Gallegos C, González N, González O, Muñoz ME. Viscous properties and microstructure of recycled eva modified bitumen. Fuel. 2004; 83(1):31-38

4. Wen G, Zhang Y, Zhang Y, Sun K, Fan Y. Rheological characterization of storage- stable SBS-modified asphalts. Polymer Testing. 2002; 21(3):295-302.

5. Yetkin Y. Polymer modified asphalt binders. Construction and Building Materials. 2007; 21(1):66-72.

6. Brulé B, Brion Y, Tanguy A. Paving Asphalt Polymer Blends: Relationships between Composition, Structure and Properties. Journal of the Association of Asphalt Paving Technologists. 1988; 57:41-64.

7. Gordon DA. Rheological properties of styrene butadiene styrene polymer modified road bitumens. Fuel. 2003; 82(14):1709-1719.

8. Leite LFM. Estudos de preparo e Caracterização de Asfaltos Modificados por Polímeros. [PhD Dissertation]. Rio de Janeiro: Universidade Federal do Rio de Janeiro; 1999.

9. Silva LS. Contribuição ao Estudo do Envelhecimento de Ligantes Asfálticos. Influência da adição de polímeros e comportamento frente à radiação UV. [PhD Dissertation]. Rio Grande do Sul: Universidade Federal do Rio Grande do Sul; 2005.

10. Xiaohu L, Isacsson U. Influence of styrene-butadiene-styrene polymer modification on bitumen viscosity. Fuel. 1997; 76(14/15):1353-1359.

11. Silva LS, Forte MMC, Vignol LA, Cardozo NSM. Study of rheological properties of pure and polymer-modified Brazilian asphalt binders. Journal of Materials Science. 2004; 39(2):539:546.

12. Dou D, Fu H, Li L, Xie L, Yao S, Yu M. Storage stability and compatibility of asphalt binder modified by SBS graft copolymer. Construction and Building Materials. 2007; 21(7):1528-1533.

13. Fawcett AH, McNally T. Blends of Bitumen with Polymers Having Styrene Component. Polymer Engineering and Science. 2001; 41(7):1251-1264.

14. Yousefi AA, Ait-Kadi A, Roy C. Effect of used-tire-derived pyrolytic oil residue on the properties of polymer-modified asphalts. Fuel. 2000; 79(8):975-986.

15. Lucena MCC. Caracterização Química e Reológica de Asfaltos Modificados por Polímeros. [PhD Dissertation]. Ceará: Universidade Federal do Ceará; 2005.

16. Petrobrás. Avaliable from: http://www2.petrobras.com.br/ingles/index. asp\#/Oil Shale: the energy of the future. Accessed on: May 13, 2008.

17. Airey GD, Rahimzadeh B, Collop AC. Linear viscoelastic limits of bituminous binders. J. Assoc. Asphalt Paving Technologists. 2002.

18. Airey GD, Hunter AE, Rahimzadeh B. The influence of geometry and sample preparation on dynamic shear rheometer testing. Proc Fourth Eur Symp Perform Bituminous Hydraul Mater Pavements; 2002; Nottingham. p. 3-12.

19. Sprecht LP. Avaliação de misturas asfálticas com a incorporação de borracha de pneus. [PhD Dissertation]. Rio Grande do Sul: Universidade Federal do Rio Grande do Sul, 2004.

20. Vlachocicova Z, Wekumbura C, Stastna J, Zanzotto L. Creep Characteristics of asphalt modified by radial styrene-butidiene-styrene copolymer. Construction and Building Materials. 2007; 21(3):567-577.

21. Sengoz B, Isikyakar G. Analysis of styrene-butadiene-styrene polymer modified using fluorescent microscopy and conventional methods. Journal of Hazardous Materials. 2008; 150(2):424-432.

22. Polacco G, Berlincioni S, Biondi D, Stastna J, Zanzotto L. Asphalt modification with different polyethylene-based polymers. European Polymer Journal. 2005; 41(12):2831-2844.

23. Levandowsky LH. Polymer Modification of Paving Asphalt Binders. Rubber Chemistry and Technology. 1994; 67(4):448-480.

24. Xiaohu L, Isacsson U. Modification of road bitumens with thermoplastic polymers. Polymer Testing. 2001; 20(1):77-86.

25. González O, Peña JJ, Muñoz ME, Santamaría A, Pérez-Lepe A, MartíezBoza F, Gallegos C. Rheological Techniques as a Tool To Analyze Polymer-Bitumen Interactions: Bitumen Modified with Polyethylene and Polyethylene-Based Blends. Energy \& Fuels. 2002; 16(5):1256-1263. 